https://doi.org/10.4322/cerind.2019.012

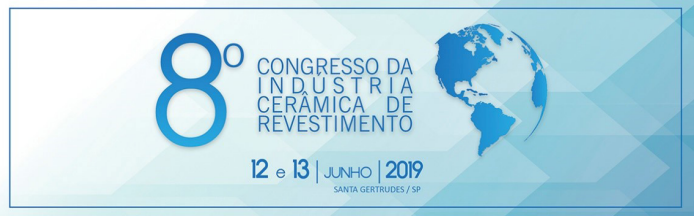

\section{A OITAVA EDIÇÃO DO CONGRESSO DA INDÚSTRIA CERÂMICA DE REVESTIMENTO, FOI UM SUCESSO}

O Objetivo do Congresso da Indústria Cerâmica de Revestimento, uma realização da ASPACER, é contribuir para o aprimoramento e atualização dos profissionais que atuam nesse setor. Para isso os trabalhos são selecionados de acordo com os interesses desses profissionais. Uma diferença significativa em relação aos congressos mais tradicionais. Além disso, considerando que esses profissionais dificilmente podem se ausentar por muito tempo das fabrica, o congresso é realizado em Santa Gertrudes, onde está o maior polo cerâmico do Brasil.

A abertura da $8^{\circ}$ edição do CICR foi com uma mesa redonda com os representantes da nova geração de 5 dos principais grupos empresariais da região falando sobre o presente e futuro do polo, fato absolutamente inédito e que contou com um público de aproximadamente 200 profissionais do setor. Dentre os diversos temas abordados, foi bastante gratificante ver que todos reconheceram a importância da qualificação dos recursos humanos e da necessidade de mais iniciativas que contribuam para o aprimoramento da formação dos profissionais. $\mathrm{Na}$ sequência tiveram lugar as apresentações dos trabalhos técnicos selecionados. Ao todo 327 profissionais que atuam no setor, de 7 Estados e 68 empresas, assistiram às palestras. Foram mais de 30 palestras técnicas sobre as diversas etapas do processo de fabricação, de insumos, técnicas de decoração, normas técnicas, etc.

Parabéns à Aspacer e aos organizadores pelo excelente congresso.

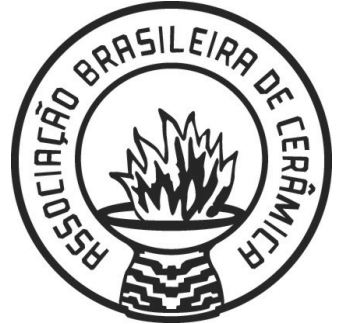

\section{Diretoria}

Presidente

Antonio Carlos de Camargo

Instituto de Pesquisas Tecnológicas do Estado de São Paulo S/A- IPT

\section{Vice-Presidente}

Edmilson Ricelli dos Passos Elfusa Geral de Eletrofusão Ltda.

\section{Diretor Administrativo-Financeiro}

Juliana Marchi

Universidade Federal do $A B C$

Diretor de Publicações

Fernando Ortega dos Santos Centro Universitário FEI

Diretor de Assuntos Empresariais

Mauro Akerman

Akerman Desenvolvimento Profissional Ltda.

\section{Diretor de Assuntos Especiais}

Edgar Dutra Zanotto

Universidade Federal de São Carlos

\section{Diretor das Comissões Técnicas}

Ulisses Soares do Prado

Lining Representação, Consultoria e Projetos Ltda.

\section{Diretor de Comunicações}

Válquiria de Fátima Justo

Escola Politécnica da Universidade de São Paulo

\section{Diretor de Eventos}

Samuel Marcio Toffoli

Escola Politécnica da USP 